\title{
Оценка влияния интенсивности межрегионального взаимодействия на пространственное развитие национальной экономики ${ }^{1}$
}

\section{Юлия Дубровская", Елена Козоногова}

Пермский национальный исследовательский политехнический университет, г. Пермь, Россия

\author{
Информация о статье \\ Поступила в редакиию: \\ 13.07.2019 \\ Принята \\ к опубликованию: \\ 15.11.2019
}

УДК $332.1,334.021$

JEL R1

\section{Ключевье слова}

межрегиональное взаимодействие, пространственное развитие, матрица сил взаимодействия, дифференциация территорий

\section{Keywords:}

interregional interaction, spatial development, matrix of interaction forces, differentiation of territories

\begin{abstract}
Аннотация
В статье актуализируется вопрос интенсификаиии межрегионального взаимодействия как значимого фактора пространственного и экономического развития. На основе использования гравитациионой модели построены матрицуы сил взаимодействия субъектов Российской Федерации. Полученные данные легли в основу эконометрической модели, оценивающей влияние интенсивности межрегионального взаимодействия на пространственное развитие. На основе результатов моделирования доказано, что увеличение уровня кооперации территорий приводит к снижению неоднородности их социчально-экономического развития.
\end{abstract}

Evaluation of the interregional cooperation influence on the spatial development of the national economy

Julia Dubrovskaya, Elena Kozonogova

\section{Abstract}

The objective of this investigation is to appraise the significance of the interregional cooperation for the economy spatial development. The investigation was carried out by the example of the Russian regions. The theoretical and methodological background for this investigation was outlined by numerous works in the field of geopolitics, production forces allocation, network economy, industrial regions development and clusters. The information and empirical basis for this research includes the information \& analytical databases available online on the site of the Russian Federal State Statistics Service, the results of the sociological surveys, media sources. To achieve the results of the investigation mathematical statistics methods including correlation and regression analysis, grouping/clustering method and cluster analysis were applied. First, the system of indicators was worked out describing the levels of scientific, infra-structural and industrial capacities development of certain territories.

\footnotetext{
${ }^{1}$ Исследование выполнено при финансовой поддержке РФФИ в рамках научного проекта № 19-010-00562

* Автор для связи: uliadubrov@mail.ru DOI: https://dx.doi.org/10.24866/2311-2271/2019-3/25-39
} 
Then the integral indices of scientific, infrastructural and industrial capacities were calculated for these regions. Second, research, sociopolitical and economic forces behind territories interaction were estimated. This made it possible to measure the interregional cooperation level of economic subjects applying the gravity model. Third, the econometric model was constructed to determine the influence of interregional cooperation on the territories differentiation level. Fourth, the impact of the changes in the level of the binterregional differentiation on the territories spatial development was assessed. The findings show a high level functional dependence of spatial development upon the effective interregional cooperation.

As for the interregional cooperation and interaction, the competitive advantages of some regions could create incentives for the economic activity growth on the territory of the others. This process will facilitate the Russia's transition to the sustainable development.

\section{Введение}

Начиная с 1990-х гг., пространственная организация экономики Российской Федерации претерпела значительную трансформацию под влиянием изменения условий международной торговли и научно-технологического развития. Кроме того, проводимая правительством в 2000-х гг. политика сфокусированного развития опорных регионов (полюсов роста) путем внедрения различных механизмов поддержки (экономические зоны, технико-внедренческие парки, бизнес-инкубаторы, кластеры и прочие) стала причиной усиления конкуренции субъектов за привлечение субсидий. Вследствие этого «современные российские условия характеризуются исключительной неоднородностью экономического и инновационного пространства страны и весьма различными экономическими и институциональными возможностями отдельных субъектов Федерации» [1].

Преодоление данных негативных тенденций, повышение общей конкурентоспособности страны и достижение устойчивого экономического роста возможно на основе перехода от модели конкурентного развития территорий, реализуемой по сценарию поляризованного роста, к модели развития на основе кооперации территорий с учетом перспективной экономической специализации. Важность интенсификации межрегионального взаимодействия, как значимого фактора пространственного и экономического развития отмечается не только многими учеными-регионалистами. Необходимость реализации потенциала межрегионального взаимодействия и повышение уровня кооперации между субъектами РФ поддерживается и на высшем уровне власти страны. Так, в феврале 2019 г. Распоряжением Правительства РФ от 13 февраля 2019 года №207-р была утверждена Стратегия пространственного развития Российский Федерации до 2025 г. (далее по тексту - Стратегия). При этом под пространственным развитием в Стратегии понимается совершенствование системы расселения и территориальной организации экономики, в том числе за счет проведения эффективной государственной политики регионального развития [2]. Отметим, что в качестве основного препятствия пространственного развития Минэкономразвития России указывается «высокий уровень межрегионального социально-экономического неравенства». В качестве инструмента решения данной проблемы ведомством предлагается развитие межрегионального взаимодействия в рамках 12 макроэкономических регионов.

Таким образом, согласно Стратегии, продуктивное межрегиональное взаимодействие способно снизить дифференциацию территориального разви- 
тия. Верификация данной гипотезы, а также оценка влияния данных экстерналий на пространственное развитие экономики явились целью настоящего исследования.

\section{Обзор литературы}

Говоря о трактовании дефиниции «межрегиональное взаимодействие» в научной литературе, отметим, что несмотря на множество определений, все они характеризуют систему отношений экономических субъектов различных регионов. Данные субъекты взаимодействуют путем различных форм кооперации и сотрудничества, в частности: взаимный обмен ресурсами (инвестиционными, трудовыми, товарными, производственными и пр.), сотрудничество в сфере научных разработок и инноваций, совместное освоение и использование природных ресурсов, сотрудничество в области разработки информационных систем, сотрудничество в сфере развития инфраструктуры (транспорт, дорожное строительство, энергетика и пр.), обмен опытом государственного и муниципального управления (разработка и реализация государственных программ и стратегий социально-экономического развития) и проч.

Обзор современной научной литературы по данному вопросу выявил, что проблемы межрегионального взаимодействия рассматриваются исследователями либо в контексте глобализации, когда хозяйствующие субъекты объединяются с целью выдержать международную конкуренцию $[3,4]$, либо в свете обеспечения предприятий региона необходимыми производственными ресурсами $[5,6,7]$, либо с целью преодоления фрагментации российского пространства и сохранения целостности страны [8]. Значительное число публикаций по данной теме исследования посвящено взаимосвязи уровней межрегионального взаимодействия и инновационной активности [9-13]. При этом практически всеми авторами признается факт того, что продуктивное межрегиональное взаимодействие положительно влияет на показатели регионального развития.

Вместе с тем, несмотря на очевидные успехи в области исследования преимуществ и перспектив межрегионального взаимодействия, достаточно фрагментарными остаются научные достижения, связанные с количественной оценкой взаимодействия хозяйствующих субъектов, функционирующих на территориях различных регионов. Отметим, что авторы большинства научных работ, посвященных проблеме изучения интенсивности межрегионального взаимодействия, основываются на оценке динамики межрегионального ввоза и вывоза товаров [14-20].

Соглашаясь с О.А. Бакуменко [21], отметим, что метод оценки динамики межрегиональных потоков ресурсов для оценки интенсивности и, соответственно, построения прогнозов перспективности взаимодействия, является узким, поскольку охватывает только одно из направлений регионального развития - экономическое, и только одну целевую группу - бизнес. Взаимодействие не может быть полным, если оно не охватывает такие основные институциональные структуры, как власть, наука и бизнес, кооперирующиеся друг с другом с целью достижения высокого уровня экономического, социального и инновационного развития территории.

По нашему мнению, наиболее оптимальное решение выявленной проблемы предложено в работе И.С. Симаровой, посвященной исследованию пространственно-экономические отношений, возникающих в процессе меж- 
и внутрирегионального взаимодействия [22]. Именно здесь сделана попытка оценки интенсивности межрегионального взаимодействия путем расчета разных типов взаимодействия: экономические силы, характеризующие массу капитала; естественные силы, определяющие ресурсный потенциал; динамические силы, описывающие поведение людей; социальные силы, возникающие как следствие взаимодействия интересов. Данная работа легла в основу предлагаемой нами методики оценки уровня межрегионального взаимодействия с целью определения значимости его влияния на пространственное развитие страны.

\section{Материалы и методы исследования}

Информационной и эмпирической основой получения количественных показателей исследования послужили базы данных Федеральной службы государственной статистики Российской Федерации, статистические данные отраслевых министерств и ведомств, региональные рейтинги специализированных организаций, нормативно-правовые акты, источники средств массовой информации.

Для получения результатов исследования были использованы методы математической статистики (корреляционный и регрессионный анализ, кластерный анализ), линейной алгебры (матрицы и действия над ними), а также гравитационная модель.

Верификация поставленной гипотезы исследования включила в себя три последовательных этапа:

Этап 1. Расчет общего уровня межрегионального взаимодействия экономических субъектов на основе гравитационной модели.

Гравитационная модель, описывающая взаимодействия между пространственными объектами (городами, регионами, странами), широко используется в региональном и пространственном анализе экономики при исследовании процессов урбанизации, размещения промышленности, экспортно-импортных взаимосвязей, миграции населения [23-25]. Известно, что закон, описывающий гравитационное взаимодействие в рамках классической механики, был открыт Ньютоном в XVII веке. Он гласит, что сила гравитационного притяжения между двумя материальными точками массы, разделенными расстоянием, пропорциональна обеим массам и обратно пропорциональна квадрату расстояния между ними.

В нашем исследовании предполагается использование гравитационной модели для оценки силы межрегионального взаимодействия. Ее применение основано на предположении о том, что величина взаимодействия пропорциональна произведению показателей значимости (величины, количества) объектов и обратно пропорциональна расстоянию между ними:

$$
F_{i j}=G \frac{q_{i} q_{j}}{d_{i j}^{2}},
$$

где $F_{i j}$ - показатель силы взаимодействия между объектами $i$ и $j, G$ - константа взаимодействия; $q$ - мера значимости объектов $j$ и $i$; $d_{i j}^{2}$ - расстояние между объектами $i$ и $j$.

Эмпирическая часть работы исходит из модели тройной спирали [26], обосновывающей три типа взаимодействия экономических субъектов (universi- 
ty - industry - government). Данные взаимодействия обусловливают связанность территорий и продуцируют три разновидности сил:

1) научно-исследовательские силы, описывающие научный потенциал региона (субъекты взаимодействия - университеты и научно-исследовательские организации);

2) социально-политические силы, описывающие инфраструктурный потенциал региона (субъект взаимодействия - органы власти);

3) экономические силы, описывающие промышленный потенциал региона (субъекты взаимодействия - предприятия).

Для вычисления сил взаимодействия нами была разработана система показателей, характеризующая уровни развития научного, инфраструктурного и промышленного потенциалов отдельных территорий, и на ее основе были рассчитаны три интегральных индекса (табл. 1).

Таблица 1

Система показателей для вычисления сил взаимодействия территорий

\begin{tabular}{|c|c|c|}
\hline $\begin{array}{c}\text { Силы } \\
\text { взаимодействия террито- } \\
\text { рий } \\
\end{array}$ & $\begin{array}{c}\text { Интегральные } \\
\text { индексы }\end{array}$ & $\begin{array}{c}\text { Показатели, формирующие интегральный } \\
\text { индекс, единицы измерения }\end{array}$ \\
\hline $\begin{array}{c}\text { Научно-исследовательские } \\
\text { силы (НИС) }\end{array}$ & $\begin{array}{c}\text { Индекс научно- } \\
\text { технического и образо- } \\
\text { вательного потенциала } \\
\text { (ИНТОП) }\end{array}$ & $\begin{array}{l}\text { - Численность персонала, занятого научными исследованиями и } \\
\text { разработками, чел. } \\
\text { - Численность студентов, обучающихся по программам бака- } \\
\text { лавриата, специалитета, магистратуры на } 10000 \text { чел. населения, } \\
\text { чел. } \\
\text { • Внутренние затраты на научные исследования и разработки, } \\
\text { ден. ед. } \\
\text { - Численность профессорско-преподавательского персонала образова- } \\
\text { тельных организаций высшего образования, чел. } \\
\text { • Доля инновационных товаров, работ, услуг от общего объема } \\
\text { отгруженных товаров, выполненных работ, услуг, \% }\end{array}$ \\
\hline $\begin{array}{c}\text { Социально-политические } \\
\text { силы (СПС) }\end{array}$ & $\begin{array}{c}\text { Индекс качества жизни } \\
\text { и инфраструктуры } \\
\text { (ИКЖИ) }\end{array}$ & $\begin{array}{l}\text { - Общая площадь жилых помещений, приходящаяся в среднем на } \\
\text { одного жителя, } \text { м }^{2} \\
\text { - Численность населения на одну больничную койку, чел. } \\
\text { - Плотность автомобильных дорог общего пользования с твердым } \\
\text { покрытием, км путей на } \\
10000 \text { км² территории } \\
\text { - Выбросы загрязняющих веществ в атмосферный воздух, отхо- } \\
\text { дящих от стационарных источников, тыс. т }\end{array}$ \\
\hline Экономические силы (ЭС) & $\begin{array}{c}\text { Индекс производ- } \\
\text { ственного потенциала } \\
\text { (ИПП) }\end{array}$ & $\begin{array}{l}\text { • Объем отгруженной продукции (работ, услуг) по виду экономиче- } \\
\text { ской деятельности «Обрабатывающие производства», ден. ед. } \\
\text { • Инвестиции в основной капитал (без бюджетных средств) на душу } \\
\text { населения, руб. } \\
\text { • Коэффициент обновления основных фондов, \% } \\
\text { - Оборот продукции (услуг), производимых малыми предприятиями, в } \\
\text { том числе микропредприятиями и индивидуальными предпринимате- } \\
\text { лями, тыс. руб. }\end{array}$ \\
\hline
\end{tabular}

Источник: составлено авторами

Отметим, что все показатели были приведены к единой шкале с помощью линейного преобразования. Интегральные индексы были получены путем нахождения среднего арифметического из соответствующих показателей.

Построение матриц сил взаимодействия по формуле 1 было выполнено в несколько шагов.

Шаг 1. Определение константы взаимодействия $G$.

Значение константы взаимодействия принимается равным единице, поскольку в отличие от физических моделей параметр не может быть достоверно оценен существующими вычислительными средствами на базе доступной информации [22]. 
Шаг 2. Вычисление промежуточных матриц (вычисление числителя формулы (1).

Поскольку индексы ИНТОП, ИКЖИ и ИПП рассчитываются для каждого региона, то мы имеем 3 вектор-столбца. Для получения промежуточных матриц $\left(\Pi_{\text {интол }}, \Pi_{\text {икжи }}, \Pi_{\text {ипп }}\right)$ необходимо вектор-столбец умножить на векторстроку, полученную транспонированием:

$$
\begin{aligned}
& \Pi_{\mathrm{M}_{\text {интоп }}=\text { ИНТОП } \times \text { ИНТОП }} \text {; П ПМ } \\
& \Pi_{\text {ИКжи }}=\text { ИКЖИ } \times \text { ИКЖ } \\
& =\text { ИПП } \times \text { ИП }^{\mathrm{T}} .
\end{aligned}
$$

Шаг 3. Определение матрицы расстояния.

Авторами для расчетов используется матрица кратчайших расстояний $D$ по автодорогам между административными центрами российских регионов [27].

Шаг 4. Построение матриц сил взаимодействия регионов.

Для оценки сил взаимодействия необходимо поэлементно разделить значения промежуточных матриц на квадрат значения матрицы расстояния.

Шаг 5. Вычисление суммарной матрицы сил взаимодействия.

Для измерения комплексного взаимодействия, имеющего различную природу, получаем суммарную матрицу, элементы которой равны среднему значению элементов трех матриц социально-политических, экономических и научно-исследовательских сил взаимодействия.

Этап 2. Расчет интегрального индекса пространственного развития

В качестве эндогенной переменной эконометрической модели был использован индекс пространственного развития территории. Для его расчета была использована система базовых принципов экономического районирования, закрепленных Стратегией пространственного развития: связанность субъектов; доступность к социальным услугам; механизмы пространственного развития экономики.

Для количественного выражения каждого принципа были определены соответствующие статистические показатели (табл. 2). Интегральный индекс пространственного развития региона был получен путем вычисления среднего значения субиндексов.

Таблииа 2

Систематизация принципов экономического районирования

\begin{tabular}{|c|c|c|}
\hline Принципы & $\begin{array}{c}\text { Субиндексы пространственно- } \\
\text { го развития } \\
\end{array}$ & Статистические показатели \\
\hline \multirow[t]{2}{*}{ Связанность территорий } & Субиндекс «Транспорт» & $\begin{array}{l}\text { - Наличие железнодорожных станций } \\
\text { - Наличие международных аэропортов } \\
\text { - Наличие выхода к международным рынкам } \\
\text { - Наличие выхода к транспортному коридору «Запад- } \\
\text { Восток» и (или) «Север-ЮГ» }\end{array}$ \\
\hline & $\begin{array}{l}\text { Субиндекс «Информационная } \\
\text { инфраструктура» }\end{array}$ & $\begin{array}{l}\text { - Средневзвешенная оценка информационной инфраструк- } \\
\text { туры }\end{array}$ \\
\hline \multirow[b]{2}{*}{$\begin{array}{l}\text { Доступность к социаль- } \\
\text { ным услугам. }\end{array}$} & Субиндекс «Образование» & - Наличие рейтинговых высших учебных заведений \\
\hline & Субиндекс «Здравоохранение» & $\begin{array}{l}\text { - Наличие диагностических центров «МРТ-Эксперт» } \\
\text { - Наличие онкологических диспансеров } \\
\text { - Количество больничных коек на } 10000 \text { человек населе- } \\
\text { ния }\end{array}$ \\
\hline $\begin{array}{lr}\begin{array}{l}\text { Механизмы } \\
\text { ственного }\end{array} & \text { простран- } \\
\text { экономики } & \text { развития } \\
\end{array}$ & $\begin{array}{l}\text { Субиндекс «Механизмы про- } \\
\text { странственного развития эконо- } \\
\text { мики» }\end{array}$ & $\begin{array}{l}\text { - Наличие индустриальных парков в регионе } \\
\text { - Наличие кластеров } \\
\text { - Наличие особых экономических зон }\end{array}$ \\
\hline
\end{tabular}
и их статистическое измерение

Источник: составлено авторами 
Концептуальный смысл первых двух принципов заключается в необходимости равномерного распределения объектов транспортной, инженерной и социальной инфраструктуры на территории субъектов РФ. Говоря о механизмах пространственного развития экономики (третий принцип), отметим, что данные инструменты крайне важны с точки зрения интенсификации экономического развития территорий и, следовательно, их наличие в регионах имеет важное, порой определяющее значение.

Остановимся подробнее на обосновании выбора статистических показателей, характеризующих принципы пространственного развития.

Учет 1 принципа, согласно Стратегии, предполагает «наличие объектов транспортной, энергетической, информационно-коммуникационной инфраструктуры, обеспечивающих связанность субъектов Российской Федерации и выход к международным рынкам или транспортным коридорам «Запад - Восток», «Север - Юг» [2].

В качестве источника данных для расчета субиндекса «Транспорт» нами был использован справочно-информационный портал в области миграционных вопросов [28]. При наличии соответствующего объекта (табл. 2) региону присваивалось значение 1 , при отсутствии - 0. Общий интегральный показатель был вычислен путём нахождения среднего арифметического.

В качестве показателя информационно-коммуникационной инфраструктуры нами выбран субиндекс «Информационная инфраструктура», который является составляющим индекса «Цифровая Россия». Данный субиндекс учитывает развитие сетей связи, цифровых технологий; наличие в субъекте объектов информационной инфраструктуры; наличие доступа у субъекта к электронно-вычислительным мощностям [29]. Нами была проведена оценка асимметрии и нормирование субиндекса «Информационная инфраструктура»

Объекты энергетической инфраструктуры нами не были учтены ввиду несомненного их наличия в каждом регионе (как минимум, в региональном центре). В итоге, при построении субиндексов «Транспорт» и «Информационная инфраструктура» было использовано 425 наблюдений.

Учет 2 принципа, согласно Стратегии, предполагает «наличие (или возможность создания) объектов отраслей социальной сферы федерального значения» [2]. Нами были выбраны важные с точки зрения жизнеобеспечения населения объекты сферы образования и здравоохранения (всего 340 наблюдений).

Информационной основой при выборе объектов из сферы образования послужил один из наиболее авторитетных независимых оценок качества обучения в российских вузах - рейтинг высших учебных заведений благотворительного фонда В. Потанина в 2016 г. (всего 85 наблюдений). При наличии в регионе ВУЗа, вошедшего в указанный рейтинг, ему присваивалось значение 1 , при отсутствии -0 .

При выборе объектов здравоохранения, мы обратились к статданным Министерства здравоохранения РФ, согласно которым основными причинами смертности в России в 2016 г. явились болезни системы кровообращении и злокачественные образования. При наличии соответствующего объекта социальной инфраструктуры в сфере здравоохранения (табл. 2), региону присваивалось значение 1, при отсутствии - 0. Далее нами была проведена оценка асимметрии и нормирование количества больничных коек на 10000 человек населе- 
ния 2016 г. В результате, интегральный субиндекс «Здравоохранения» был вычислен путем нахождения среднего арифметического.

Учет 3 принцииа предполагает наличие в регионе механизмов пространственного развития экономики (всего 255 наблюдений). Нами были выбраны следующие показатели: индустриальные парки (при условии членства региона в ассоциации индустриальных парков России); кластеры (согласно реестру кластеров Министерства промышленности РФ); особые экономические зоны (в соответствии с проектом «Россия. Особые экономические зоны»). При наличии указанных объектов региону присваивалось значение 1 , при отсутствии -0 . Общий интегральный показатель «Механизмы пространственного развития экономики» был определен в соответствии со следующей шкалой: 1 - все объекты присутствуют; 0,6 - есть 2 объекта; 0,3 - есть 1 объект; 0 - нет объектов.

Этап 3. Построение эконометрической модели, оценивающей влияние интенсивности межрегионального взаимодействия на индекс пространственного развития регионов.

\section{Результаты исследования и их обсуждение}

В результате вычислений авторами были получены матрицы сил взаимодействия для 85 регионов России по статистическим данным за 2016 год. Для лучшего понимания величины силы связи между регионами, каждая матрица сил взаимодействия была нормирована по столбцам и полученные значения переведены в проценты. Более подробно нами было проанализировано взаимодействие Приморского края с другими регионами.

Из табл. 3 видно, что самые сильные социально-политические связи Приморский край имеет с Хабаровским краем, Еврейской АО и Амурской областью.

Таблица 3

Матрица социально-политических сил взаимодействия (фрагмент матрицы для Приморского края), \%

\begin{tabular}{|c|c|c|c|c|c|c|c|c|c|}
\hline & 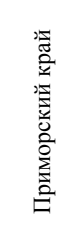 & 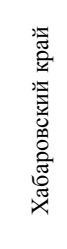 & 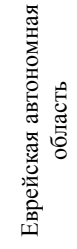 & 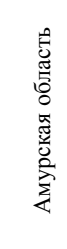 & 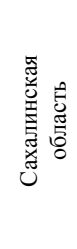 & 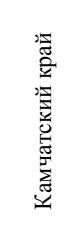 & 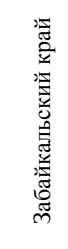 & 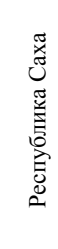 & 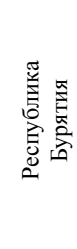 \\
\hline Приморский край & 0,00 & 4,24 & 3,43 & 4,63 & 7,71 & 3,19 & 1,69 & 3,05 & 0,70 \\
\hline Хабаровский край & 28,18 & 0,00 & 74,83 & 17,64 & 22,54 & 4,78 & 2,73 & 4,67 & 0,99 \\
\hline Еврейская автономная область & 24,97 & 82,02 & 0,00 & 45,15 & 21,74 & 5,74 & 4,55 & 7,63 & 1,58 \\
\hline Амурская область & 8,46 & 4,85 & 11,33 & 0,00 & 8,09 & 3,41 & 5,70 & 9,07 & 1,74 \\
\hline Сахалинская область & 7,57 & 3,33 & 2,93 & 4,35 & 0,00 & 10,55 & 1,73 & 3,15 & 0,73 \\
\hline Камчатский край & 2,39 & 0,54 & 0,59 & 1,40 & 8,05 & 0,00 & 1,02 & 5,00 & 0,50 \\
\hline Забайкальский край & 2,03 & 0,50 & 0,75 & 3,76 & 2,13 & 1,63 & 0,00 & 6,19 & 17,55 \\
\hline Республика Саха & 1,55 & 0,36 & 0,53 & 2,52 & 1,63 & 3,38 & 2,61 & 0,00 & 0,94 \\
\hline Республика Бурятия & 1,32 & 0,28 & 0,41 & 1,80 & 1,40 & 1,26 & 27,47 & 3,48 & 0,00 \\
\hline
\end{tabular}

Источник: составлено авторами 
Приморский край имеет устойчивые экономические связи с Хабаровским краем, Еврейской автономной областью, но на пятом месте по силе взаимодействия стоит Республика Саха (табл. 4).

Таблица 4

Матрица экономических сил взаимодействия

(фрагмент матрицы для Приморского края), \%

\begin{tabular}{|c|c|c|c|c|c|c|c|c|c|}
\hline & 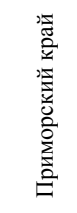 & 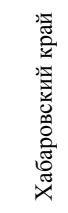 & 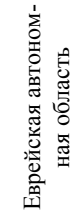 & 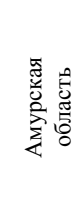 & 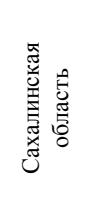 & 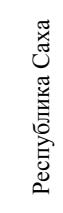 & 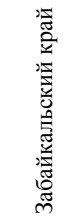 & 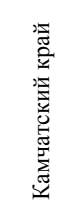 & 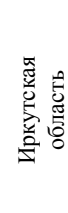 \\
\hline Приморский край & 0,00 & 6,72 & 2,81 & 5,16 & 7,72 & 2,89 & 1,54 & 2,99 & 0,51 \\
\hline Хабаровский край & 35,80 & 0,00 & 78,61 & 25,23 & 28,94 & 5,67 & 3,19 & 5,74 & 0,87 \\
\hline Еврейская автономная область & 13,42 & 70,40 & 0,00 & 27,31 & 11,80 & 3,92 & 2,24 & 2,92 & 0,57 \\
\hline Амурская область & 8,16 & 7,48 & 9,04 & 0,00 & 7,89 & 8,36 & 5,05 & 3,12 & 1,09 \\
\hline Сахалинская область & 7,52 & 5,29 & 2,41 & 4,86 & 0,00 & 2,99 & 1,58 & 9,90 & 0,54 \\
\hline Республика Саха & 2,94 & 1,08 & 0,84 & 5,38 & 3,12 & 0,00 & 4,55 & 6,09 & 1,23 \\
\hline Забайкальский край & 2,09 & 0,81 & 0,64 & 4,34 & 2,21 & 6,08 & 0,00 & 1,59 & 6,09 \\
\hline Камчатский край & 1,91 & 0,69 & 0,39 & 1,26 & 6,51 & 3,83 & 0,75 & 0,00 & 0,34 \\
\hline Иркутская область & 1,63 & 0,52 & 0,38 & 2,20 & 1,76 & 3,86 & 14,33 & 1,68 & 0,00 \\
\hline
\end{tabular}

Источник: составлено авторами

В плане научно-исследовательской связанности, самая сильное взаимодействие зафиксировано с Хабаровским краем, на пятом месте по силе связи Забайкальский край (табл. 5).

Таблииа 5

Матрица научно-исследовательских сил взаимодействия (фрагмент матрицы для Приморского края), \%

\begin{tabular}{|c|c|c|c|c|c|c|c|c|c|}
\hline & 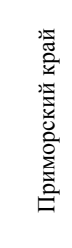 & 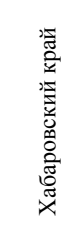 & 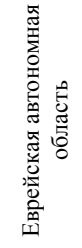 & 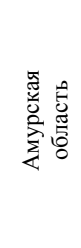 & 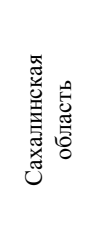 & 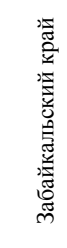 & 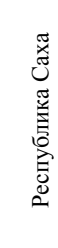 & 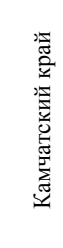 & 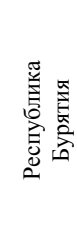 \\
\hline Приморский край & 0,00 & 9,57 & 2,58 & 6,07 & 8,57 & 1,74 & 3,74 & 4,40 & 0,71 \\
\hline Хабаровский край & 47,40 & 0,00 & 84,94 & 34,86 & 37,78 & 4,23 & 8,62 & 9,93 & 1,52 \\
\hline Еврейская автономная область & 10,14 & 67,33 & 0,00 & 21,54 & 8,79 & 1,70 & 3,40 & 2,88 & 0,58 \\
\hline Амурская область & 6,86 & 7,96 & 6,20 & 0,00 & 6,54 & 4,26 & 8,07 & 3,42 & 1,29 \\
\hline Сахалинская область & 4,20 & 3,73 & 1,10 & 2,83 & 0,00 & 0,88 & 1,92 & 7,22 & 0,37 \\
\hline Забайкальский край & 2,05 & 1,01 & 0,51 & 4,45 & 2,14 & 0,00 & 6,86 & 2,04 & 16,16 \\
\hline Республика Саха & 1,92 & 0,90 & 0,45 & 3,67 & 2,01 & 2,98 & 0,00 & 5,20 & 1,06 \\
\hline Камчатский край & 1,68 & 0,77 & 0,28 & 1,16 & 5,65 & 0,66 & 3,87 & 0,00 & 0,32 \\
\hline Республика Бурятия & 1,59 & 0,69 & 0,33 & 2,55 & 1,68 & 30,56 & 4,62 & 1,88 & 0,00 \\
\hline
\end{tabular}

Источник: составлено авторами

В итоге Приморский край демонстрирует наиболее существенные связи различной природы со Хабаровским краем, Еврейской автономной областью и Амурской областью (табл. 6). 
Суммарная матрица сил взаимодействия

(фрагмент матрицы для Приморского края), \%

\begin{tabular}{|c|c|c|c|c|c|c|c|c|c|}
\hline & 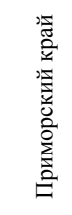 & 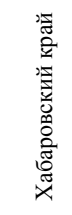 & 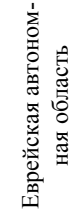 & 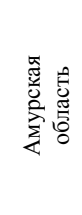 & 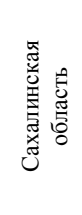 & 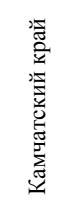 & 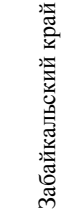 & 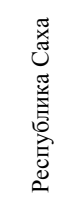 & 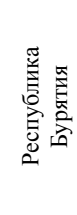 \\
\hline Приморский край & 0,00 & 5,71 & 3,21 & 4,97 & 7,83 & 3,33 & 1,67 & 3,15 & 0,67 \\
\hline Хабаровский край & 34,26 & 0,00 & 76,99 & 21,93 & 25,96 & 5,71 & 3,17 & 5,80 & 1,13 \\
\hline Еврейская автономная область & 19,28 & 77,21 & 0,00 & 37,98 & 17,93 & 4,82 & 3,42 & 5,62 & 1,14 \\
\hline Амурская область & 8,01 & 5,90 & 10,19 & 0,00 & 7,83 & 3,36 & 5,23 & 8,65 & 1,54 \\
\hline Сахалинская область & 6,73 & 3,72 & 2,56 & 4,17 & 0,00 & 9,94 & 1,50 & 2,84 & 0,60 \\
\hline Камчатский край & 2,13 & 0,61 & 0,51 & 1,33 & 7,40 & 0,00 & 0,88 & 4,41 & 0,42 \\
\hline Забайкальский край & 2,05 & 0,65 & 0,70 & 3,98 & 2,14 & 1,69 & 0,00 & 6,30 & 16,51 \\
\hline Республика Саха & 1,89 & 0,58 & 0,56 & 3,21 & 1,98 & 4,13 & 3,08 & 0,00 & 1,05 \\
\hline Республика Бурятия & 1,34 & 0,38 & 0,38 & 1,90 & 1,39 & 1,30 & 26,79 & 3,48 & 0,00 \\
\hline
\end{tabular}

Источник: составлено авторами

Далее мы оценили влияния интенсивности межрегионального взаимодействия на пространственное развитие субъектов РФ. При этом нами был учтен характер сил взаимодействия. Для построения модели на основании значений матриц сил взаимодействия для каждого региона были вычислены средние значения сил взаимодействия.

С целью визуализации рассчитанного нами значения индекса пространственного развития регионов РФ мы построили карту (рис. 1). Все регионы были разделены на 4 группы. В первую группу (первый квартиль) вошли регионы со значением индекса пространственного развития менее 0,304; во вторую (второй квартиль) - от 0,305 до 0,450; в третью (третий квартиль) - от 0,451 до 0,674; в четвертую (четвертый квартиль) - от 0,675 до 0,951. При этом минимальное значение индекса пространственного развития имеет Республика Алтай, а максимальное - Московская область.

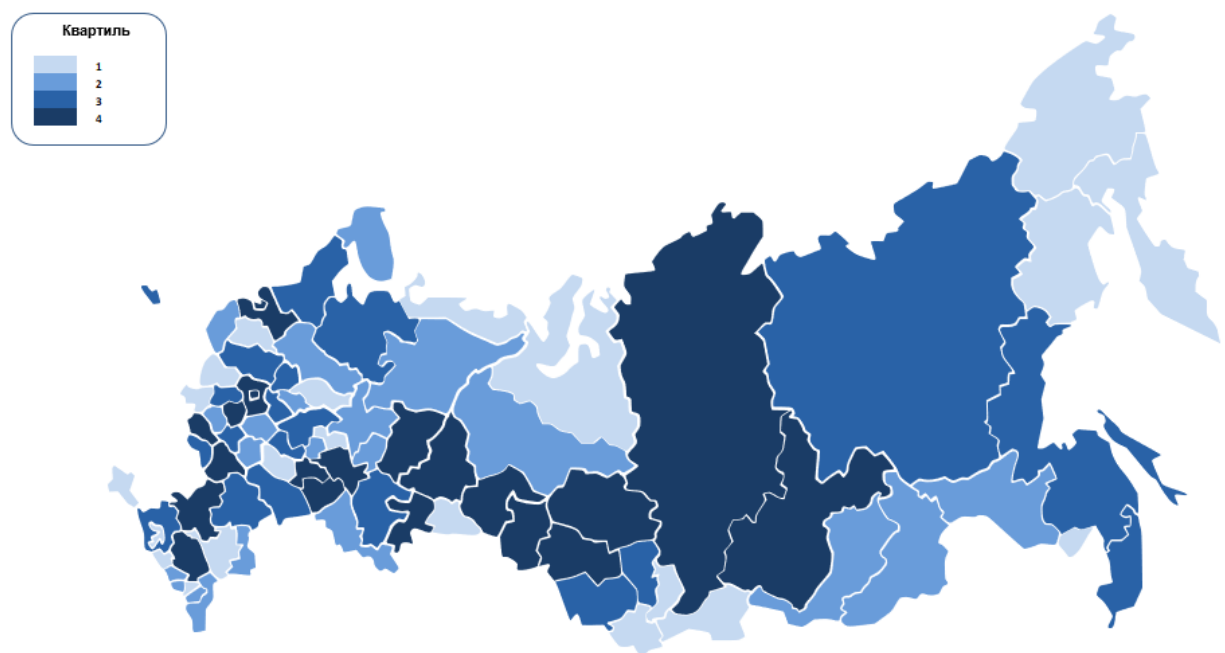

Рuc. 1. Индекс пространственного развития в регионах России 
В табл. 7 представлены результаты оценки влияния интенсивности межрегионального взаимодействия на пространственное развитие регионов. При этом интенсивность взаимодействия регионов выражена суммарной матрицей сил взаимодействия, а пространственное развитие территорий - показателем «Индекс пространственного развития».

Таблица 7

Результаты корреляционно-регрессионного анализа

\begin{tabular}{|c|c|c|}
\hline \multirow{2}{*}{ Переменные } & \multicolumn{2}{|c|}{ Логарифм индекса пространственного развития } \\
\cline { 2 - 3 } & $2,3883^{* * *}$ & Модель 2 \\
\hline \multirow{2}{*}{ Свободный член } & $(0,5031)$ & 0,4393 \\
& & $(0,4859)$ \\
\hline \multirow{2}{*}{ Ln_CВC } & $-0,7457^{* * *}$ & $\left(0,035^{* *}\right.$ \\
& $(0,1003)$ & \\
\hline Ln_CПC & $0,3378^{* * *}$ & \\
& $(0,1039)$ & \\
\hline \multirow{2}{*}{ Ln_ЭC } & $0,5597^{* * *}$ & \\
\hline \multirow{2}{*}{ Ln_НИC } & $(0,1066)$ & 0,08 \\
\hline N & 340 & \\
\hline R2 & 0,48 & \\
\hline
\end{tabular}

Примечание: В скобках указаны стандартные ошибки

$* * * p<0,01 ; * * p<0,05 ; * p<0,1$

Источник: составлено авторами

Модель 1 оценивает влияние социально-политических (СПС), экономических (ЭС) и научно-исследовательских (НИС) сил взаимодействия на индекс пространственного развития регионов.

По результатам оценивания, статистически значимо на индекс пространственного развития влияют все три типа сил взаимодействия. При этом, повышение уровней экономического и научно-исследовательского взаимодействий ведет к увеличению индекса пространственного развития, что является вполне ожидаемым результатом. Однако повышение уровня социально-политического взаимодействия между регионами, инициатором которого согласно предпосылке построенной модели является государство, напротив, ведет к снижению значения индекса пространственного развития. Считаем, что данный результат объясняется проводимой политикой «оптимизации», смысл которой состоит в укрупнении сети бюджетных учреждений в сфере здравоохранения и образования. Так, например, проведение Минобрнауки и Рособрнадзором активной работы по «расчистке» рынка высшего образования от программ низкого качества привело к тому, что с 2011 по 2017 гг. сеть филиалов вузов сократилась наполовину [30]. Объективно, данные действия приводят к повышению дифференциации в уровнях доступности населения к социальным услугам в различных регионах.

\section{Заключение}

Проведенное исследование подтвердило предположение о том, что продуктивное межрегиональное взаимодействие является значимым фактором пространственного развития. Практическое значение модели заключается в возможности применения полученных результатов при разработке региональных политик развития с целью усиления межрегиональной кооперации и, как следствие, повышения уровня пространственной однородности территорий. 


\section{Сиисок источников / References}

1. Бухвальд Е.М. Субъекты Федерации в системе стратегического планирования. Вестник Рос. академии естественных наук, 2015, T. 15, № 2, сc. 7-10. [Bukhval'd Ye.M. Subyekty Federatsii v sisteme strategicheskogo planirovaniya [Subjects of the Federation in the system of strategic planning]. Vestnik Ros. akademii yestestvennykh nauk = Herald Ros. Academy of Natural Sciences, 2015, vol. 15, no 2, pp. 7-10].

2. Стратегия пространственного развития Российской Федерации до 2025 года. Официальный сайт Минэкономразвития России [Strategiya prostranstvennogo razvitiya Rossiyskoy Federatsii do 2025 goda [Spatial Development Strategy of the Russian Federation until 2025]. Ofitsial'nyy sayt Minekonomrazvitiya Rossii = Official website of the Ministry of Economic Development of Russia]. Available at: http://economy.gov.ru/minec/activity/sections/planning/sd/201817081 (accessed 02.07.2019).

3. Torre A., Rallet A. Proximity and Localization. Regional Studies, 2005, Vol. 39.1, pp. 47-59.

4. Овчаренко Н.Е. Модели современных интеграционных процессов. М., 2001 [Ovcharenko N.Ye. Modeli sovremennykh integratsionnykh protsessov [Models of modern integration processes]. M., 2001]. Available at: http://www.xserver.ru/user/msipr.

5. Pyke F., Sengenberger W. Industrial districts and local economic regeneration, Geneva: ILO, 1992.

6. Song W. Regionalization, inter-regional cooperation and global governance, Springer-Verlag, 2007.

7. Плихун О.Г., Киселев А.М. Вопросы межрегионального и приграничного сотрудничества Омской области. Вестник Омского университета. Экономика, 2009, № 3, сс. 56-59 [Plikhun O.G., Kiselev A.M. Voprosy mezhregional'nogo i pri-granichnogo sotrudnichestva Omskoy oblasti [Issues of interregional and border cooperation of the Omsk region]. Vestnik Omskogo universiteta. Ekonomika = Bulletin of Omsk University. Economy, 2009, no 3, pp. 5659].

8. Золотарев Н.П. Совершенствование механизма экономического взаимодействия регионов Сибири (на примере межрегиональной ассоциации «Сибирское соглашение». Автореф. дис. ... канд. экон. наук. Барнаул, 2006 [Zolotarev N.P. Sovershenstvovaniye mekhanizma ekonomicheskogo vzaimodeystviya regionov Sibiri (na primere mezhregional'noy assotsiatsii «Sibirskoye soglasheniye». Avtoref. dis. ... kand. ekon. Nauk [Improving the mechanism of economic interaction of the regions of Siberia (on the example of the inter-regional association "Siberian Accord". Abstract of thesis ... Ph.D. in Economics]. Barnaul, 2006].

9. Fritsch M., Lukas R. Innovation, cooperation, and the region. Papers 98/1, Bergakademie Freiberg, Faculty of Economics and Business Administration, 1998.

10. Audretsch David B., Thurik Roy. Innovation, Industry Evolution and Employment. Cambridge: Cambridge University Press, 1999

11. Fritsch M. Does R\&D-cooperation behavior differ between regions? Industry and Innovation, 2003, vol. 10, no 1, pp. 25-39.

12. Никулина И.Е., Бурец Ю.С. Формирование межрегионального взаимодействия в сфере инновационной деятельности на основе диагностики разрывов инновационного процесса. Экономика и предпринимательство, 2016, № 12-2 (77-2), сc. 346-349 [Nikulina I.Ye., Burets YU.S. Formirovaniye mezhregional'nogo vzaimodeystviya $\mathrm{v}$ sfere innovatsionnoy deyatel'nosti na osnove diagnosti-ki razryvov innovatsionnogo protsessa [Formation of interregional cooperation in the field of innovation on the basis of diagnostics of breaks in the innovation process]. Ekonomika i predprinimatel'stvo = Economics and Entrepreneurship, 2016, no 122 (77-2), pp. 346-349].

13. Золотарев Н.П. Механизм межрегионального экономического взаимодействия в инновационной сфере: потребность развития, сущность, показатели оценки. Вестник ТГПУ, 2012, № 12(127), cc. 127-132 [Zolotarev N.P. Mekhanizm mezhregional'nogo ekonomicheskogo vzaimodeystviya $\mathrm{v}$ innovatsionnoy sfere: potrebnost' razvitiya, sushchnost', pokazateli 
otsenki [The mechanism of interregional economic interaction in the innovation sphere: the need for development, the essence, the assessment indicators]. Vestnik TGPU = Herald TSPU, 2012, no 12(127), pp. 127-132].

14. Гибадуллин М.3., Артамонычева А.Р. Межрегиональные экономические связи Чувашской Республики: тенденции и перспективы. Вестник Чувашского университета, 2013, № 2, cc. 249-253 [Gibadullin M.Z., Artamonycheva A.R. Mezhregional'nyye eko-nomicheskiye svyazi Chuvashskoy Respubliki: tendentsii i perspektivy [Interregional economic relations of the Chuvash Republic: trends and prospects]. Vestnik Chuvashskogo universiteta $=$ Bulletin of the Chuvash University, 2013, no 2, pp. 249-253].

15. Аджикова А.С., Школьникова Н.Н. Интеграция регионов и качество экономического пространства. Вестник Волгоградского государственного университета. Серия 3. Экономика. Экология, 2016, № 2 (35), сc. 18-26 [Adzhikova A.S., Shkol'nikova N.N. Integratsiya regionov i kachestvo ekonomicheskogo prostranstva [Integration of regions and the quality of economic space]. Vestnik Volgogradskogo gosudarstvennogo universiteta. Seriya 3. Ekonomika. Ekologiya $=$ Bulletin of the Volgograd State University. Series 3. Economy. Ecology, 2016, no 2 (35), pp. 18-26].

16. Белоусова А.В. Межрегиональные взаимодействия: влияние на экономику региона (Хабаровский край). Пространственная экономика, 2012, № 4, cc. 127-137 [Belousova A.V. Mezhregional'nyye vzaimodeystviya: vliyaniye na ekonomiku regiona (Khabarovskiy kray) [Interregional interaction: the impact on the economy of the region (Khabarovsk Territory)]. Prostranstvennaya ekonomika = Spatial Economics, 2012, no 4, pp. 127-137].

17. Стасюлис М.В. Развитие агропродовольственного рынка юга Сибири на основе межрегиональных продовольственных связей. Автореф. дис. ... канд. экон. наук. Новосибирск, 2015. 22 c. [Stasyulis M.V. Razvitiye agroprodovol'stvennogo rynka yuga Sibiri na osnove mezhregional'nykh prodovol'stvennykh svyazey. Avtoref. dis. ... kand. ekon. Nauk [The development of the agri-food market in the south of Siberia based on inter-regional food links. Author's abstract dis. ... Cand. econ sciences]. Novosibirsk, 2015. 22 p.].

18. Золотарев Н.П. Совершенствование механизма экономического взаимодействия регионов Сибири. Автореф. дис. ... канд. экон. наук. Барнаул, 2006. 28 с. [Zolotarev N.P. Sovershenstvovaniye mekhanizma ekonomicheskogo vzaimodeystviya regionov Sibiri. Avtoref. dis. ... kand. ekon. Nauk [Improving the mechanism of economic interaction of the regions of Siberia. Author's abstract dis. ... Cand. econ sciences]. Barnaul, 2006. 28 p.]

19. Григорян К.А., Рязанов В.В. Межрегиональное взаимодействие в условиях перехода к шестому технологическому укладу. Вектор науки ТГУ. Серия: Экономика и управление, 2018, № 1 (32), cc. 19-24 [Grigoryan K.A., Ryazanov V.V. Mezhregional'noye vzaimodeystviye $\mathrm{v}$ usloviyakh perekhoda $\mathrm{k}$ shestomu tekhnologicheskomu ukladu [Interregional cooperation in the transition to the sixth technological order]. Vektor nauki TGU. Seriya: Ekonomika $i$ upravleniye = TSU science vector. Series: Economics and Management, 2018, no 1 (32), pp. 19-24].

20. Ускова Т.В., Лукин Е.В. Межрегиональное взаимодействие как фактор роста экономики. Вологда: ИСЭРТ РАН, 2013. 76 c. [Uskova T.V., Lukin Ye.V. Mezhregional'noye vzaimodeystviye kak faktor rosta ekonomiki [Interregional interaction as a factor in economic growth]. Vologda: ISERT RAN, 2013. 76 p.]

21. Бакуменко O.А. Межрегиональное взаимодействие как фактор развития региональных социально-экономических систем (на примере Северо-Западного федерального округа). Дис. ... канд. экон. наук. Псков, 2017. 179 с. [Bakumenko O.A. Mezhregional'noye vzaimodeystviye kak faktor razvitiya regional'nykh sotsial'no-ekonomicheskikh sistem (na primere Se-vero-Zapadnogo federal'nogo okruga). Dis. ... kand. ekon. Nauk [Interregional interaction as a factor in the development of regional socio-economic systems (on the example of the NorthWest Federal District). Dis. ... Cand. econ sciences]. Pskov, 2017. 179 p.]. Available at: http://www.iresras.ru/uploads/2017/Dissertaciya\%20Bakumenko.pdf.

22. Симарова И.С. Обоснование регионального развития с учетом связанности экономического пространства. Автореф. дис. ... канд. экон. наук. Тюмень, 2014. 24 с. [Simarova I.S. Obosnovaniye regional'nogo razvitiya s uchetom svyazannosti ekonomicheskogo prostranstva. 
Avtoref. dis. ... kand. ekon. Nauk [Rationale for regional development, taking into account the connectedness of the economic space. Author's abstract dis. ... Cand. econ sciences]. Tyumen, 2014. 24 p.] Available at: http://vak.ed.gov.ru/az/server/php/filer.php?table=att_case\&fld=autoref\&key[]=168019

23. Ageliki A., Ioannis P. Eurasian orientation and global trade international: the case of Turkey. Eurasian Economic Review, 2016, No. 6(2), pp. 275-287.

24. Karagoz K., Saray M. Ozan. Trade potential of Turkey with Asia-Pacific countries: Evidence from panel gravity model. International Economic Studies, 2010, no. 36(1), pp. 19-26.

25. Suvankulov F., Guc Y. Who is trading well in Central Asia? A gravity analysis from exports from the regional powers to the region. Eurasian Journal of Business and Economics, 2012, No. 5(9), pp. 21-43.

26. Leydesdorff L. The Triple Helix of University-Industry-Government Relations. University of Amsterdam, Amsterdam School of Communication Research (ASCoR), 2012. Available at: http://www.leydesdorff.net (accessed 23.06.2019).

27. Козоногова Е.В. Регулирование взаимодействия хозяйствующих субъектов РФ на основе экономико-математической идентификации межрегиональных кластеров. Дис. ... канд. экон. наук. Пермь, 2019. 178 с. [Kozonogova Ye.V. Regulirovaniye vzaimodeystviya khozyaystvuyu-shchikh subyektov RF na osnove ekonomiko-matematicheskoy identifikatsii mezhregional'nykh klasterov. Dis. ... kand. ekon. Nauk [Regulation of the interaction of economic entities of the Russian Federation on the basis of economic and mathematical identification of interregional clusters. Dis. ... Cand. econ sciences.]. Perm, 2019. 178 p.]

28. Железнодорожные вокзалы и станции Пермского края. Справочно-информационный портал в области миграционных вопросов [Zheleznodorozhnyye vokzaly i stantsii Permskogo kraya [Railway stations and stations of the Perm region]. Spravochnoinformatsionnyy portal $v$ oblasti migratsionnykh voprosov $=$ Reference and information portal in the field of migration issues]. Available at: http://zagranguru.ru/railway/permskij-kraj/ (accessed 24.06.2019).

29. Индекс «Цифровая Россия». Официальный сайт Московской школь управления Сколково [Indeks «Tsifrovaya Rossiya» [Index "Digital Russia"]. Ofitsial'nyy sayt Moskovskoy shkoly upravleniya Skolkovo = The official website of the Moscow School of Management Skolkovo]. Available at: https://finance.skolkovo.ru/ru/sfice/research-reports/1779-2018-10-001-ru/ (accessed 24.06.2019).

30. Габдрахманов Н. К. Концентрация студентов в системе высшего образования на карте Российской Федерации. Вестник Российского университета дружбы народов. Серия: Экономика, 2019, т. 27, № 1, сc. 7-17 [Gabdrakhmanov N. K. Kontsentratsiya studentov v sisteme vysshe-go obrazovaniya na karte Rossiyskoy Federatsii [The concentration of students in the system of higher education on the map of the Russian Federation]. Vestnik Rossiyskogo universiteta druzhby narodov. Seriya: Ekonomika = Bulletin of the Russian University of Friendship of Peoples. Series: Economics, 2019, vol. 27, no. 1, pp. 7-17].

\section{Сведения об авторах / About authors}

Дубровская Юлия Владимировна, кандидат экономических наук, доцент кафедры экономики и финансов, Гуманитарный факультет, Пермский национальный исследовательский политехнический университет. 614046 Россия, г. Пермь, Комсомольский проспект, 29.

E-mail: uliadubrov@mail.ru

Julia V. Dubrovskaya, Candidate of Economic Sciences, Associate Professor, Department of Economics and Finances, Perm National Research Polytechnic University, Perm, Russia, Komsomolsky prospect, 29. 614046.E-mail: uliadubrov@mail.ru 
Ю.В. Аубровская, Е.В. Козоногова // Известия АВФУ. Экономика и управление. 3. 209. 25-39

Козоногова Елена Викторовна, кандидат экономических наук, ассистент кафедры экономики и финансов, Гуманитарный факультет, Пермский национальный исследовательский политехнический университет. 614046 Россия, г. Пермь, Комсомольский проспект, 29.

E-mail: elena.kozongova@gmail.com

Elena V. Kozonogova, Assistant, Department of Economics and Finances, Perm National Research Polytechnic University, Perm, Russia, Komsomolsky prospect, 29. 614046.

E-mail: elena.kozongova@gmail.com 